\title{
Novel syntheses of $\beta$-0-4 type oligomeric lignin model compounds by nucleophilic addition of carbanion to the aldehyde group
}

Key words Lignin $\cdot \beta-O-4 \cdot$ Synthesis $\cdot$ Oligomeric lignin model compounds

\section{Introduction}

Guaiacylglycerol- $\beta$-guaiacyl ether has been widely utilized as a model for the $\beta-O-4$ substructure, the predominant structure in lignins, ${ }^{1}$ to study the chemical reactivity ${ }^{2}$ and biodegradability of lignin. However, it is becoming increasingly important to use model compounds with higher molecular weight, because these compounds are more appropriate than a dimeric compound for mimicking the lignin structure. For this purpose, Iikka et al. $^{3}$ reported the stepwise syntheses of hexameric models. These syntheses contained twelve reaction steps and resulted in low overall yields $(<13 \%)$. Thus, a novel synthetic method which affords higher molecular weight lignin model compounds in high yields and with fewer reaction steps is required.

Here, we propose a novel synthetic method for obtaining lignin oligomers that are composed of only the $\beta-O-4$ structure. This method consists of two reaction steps: the continuous nucleophilic addition oligomerization of $t$-butoxycarbonylmethyl vanillin (1) and subsequent reduction of the oligomeric $\beta$-hydroxyl ester (Fig. 1).

\section{Results and discussion}

The synthetic method for producing an arylglycerol- $\beta$-aryl ether from the condensation reaction of ethyl 2methoxyphenoxy acetate and vanillin was developed by Nakatsubo et al. ${ }^{4}$ In this method, a $\mathrm{C} \alpha-\mathrm{C} \beta$ bond is formed

R. Katahira $\cdot$ H. Kamitakahara · T. Takano $\cdot$ F. Nakatsubo $(\square)$ Division of Forest and Biomaterials Science, Graduate School of Agriculture, Kyoto University, Oiwake-cho, Kitashirakawa,

Sakyo-ku, Kyoto 606-8502, Japan

Tel. +81-75-753-6256; Fax +81-75-753-6300

e-mail: tsubosan@kais.kyoto-u.ac.jp by the nucleophilic addition of a carbanion, which is produced from ethyl 2-methoxyphenoxy acetate in the presence of lithium diisopropylamide (LDA), to the aldehyde group of vanillin. Trimer ${ }^{3,5,6}$ and tetramer ${ }^{5,7}$ model compounds have also been synthesized in a stepwise manner or by a convergent synthetic method. The condensation reaction may also be applied to the present investigation. In accordance with our basic strategy, when a compound having both an ester that contains $\alpha$-hydrogens and an aldehyde group in the same molecule is treated with LDA, intermolecular condensation is expected to yield oligomers or polymers.

In this investigation, $t$-butoxycarbonylmethyl vanillin, which was prepared from vanillin and $t$-butyl bromoacetate in $87 \%$ yield, was selected as a starting material. To a stirred solution of $t$-butoxycarbonylmethyl vanillin $(2.66 \mathrm{~g}$, $10 \mathrm{mmol}$ ) in anhydrous tetrahydrofuran (THF) $(40 \mathrm{ml}), 5 \mathrm{ml}$ of LDA (10 mmol) (2.0M solution in heptane/THF/ ethylbenzene, Aldrich) was added dropwise at $-30^{\circ} \mathrm{C}$ over a period of $30 \mathrm{~min}$. After additional stirring for $30 \mathrm{~min}$ at the same temperature, the stirring was continued for an additional $1.5 \mathrm{~h}$ at $0^{\circ} \mathrm{C}$. After neutralization with $1 \mathrm{~N} \mathrm{HCl}$, the reaction mixture was partitioned between ethyl acetate and brine. The organic layer was dried over $\mathrm{Na}_{2} \mathrm{SO}_{4}$ and evaporated to dryness to give a crude yellow oil. The yellow oil was applied to a short silica gel column and was eluted with dichloromethane to remove monomer and dimer and to give a yellow solid (2) $(2.32 \mathrm{~g}, 90 \%)$. The low molecular weight fraction (monomer and dimer) removed during the purification was $0.24 \mathrm{~g}(9.1 \%)$. On the ${ }^{1} \mathrm{H}-\mathrm{NMR}$ spectrum of compound 2 (Fig. 2), each peak was assigned as follows: $t$-butyl-H $(\delta 1.23, \mathrm{~s}, 1.29, \mathrm{~s}, 1.46, \mathrm{~s}), \mathrm{OCH}_{3}(\delta 3.85-3.95, \mathrm{~m})$, $\mathrm{H} \beta(\delta 4.35, \mathrm{~m}, 4.63, \mathrm{~s}, 4.81, \mathrm{~m}),-\mathrm{C}_{2} \mathrm{COO}^{t} \mathrm{Bu}(\delta 4.56, \mathrm{~s}), \mathrm{H} \alpha$ $(\delta 5.00, \mathrm{~d}, J=6.9 ; 5.11, \mathrm{~s}, 5.18, \mathrm{~m})$, Arom.-H $(\delta 6.72-7.42, \mathrm{~m})$, CHO $(\delta 9.85, \mathrm{~s})$. Thus, ${ }^{1} \mathrm{H}-\mathrm{NMR}$ data supported identification of the product structure to be that of the expected poly $\beta$-hydroxyl esters. Mass spectra were recorded on a Bruker REFLEX III MALDI-TOF mass spectrometer. 2-(4Hydroxyphenylazo)-benzoic acid was used as the matrix and angiotensin II and insulin bovine were used as standards. On the basis of MALDI-TOF mass spectrometric 

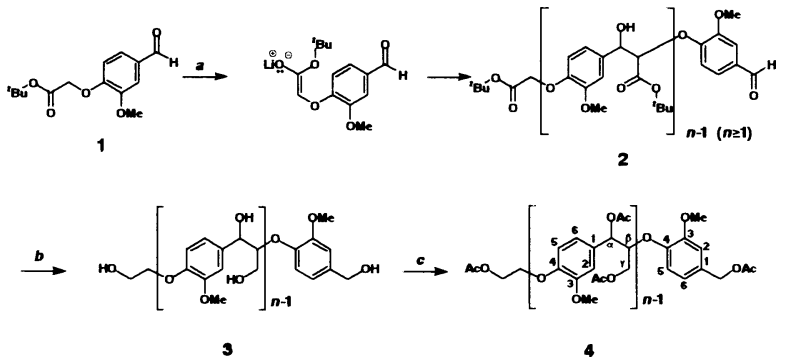

Fig. 1. Synthetic route of $\beta-O-4$ type oligomeric lignin model compound $3,{ }^{a} \mathrm{LDA} /$ anhydrous THF $/-30{ }^{\circ} \mathrm{C} / 2.5 \mathrm{~h},{ }^{b} \mathrm{LiAlH}_{4} /$ anhydrous $\mathrm{THF} / 60^{\circ} \mathrm{C} / 3 \mathrm{~h},{ }^{c} \mathrm{Ac}_{2} \mathrm{O} /$ pyridine $(1: 1, \mathrm{v} / \mathrm{v}) / 50^{\circ} \mathrm{C} / 12 \mathrm{~h}$

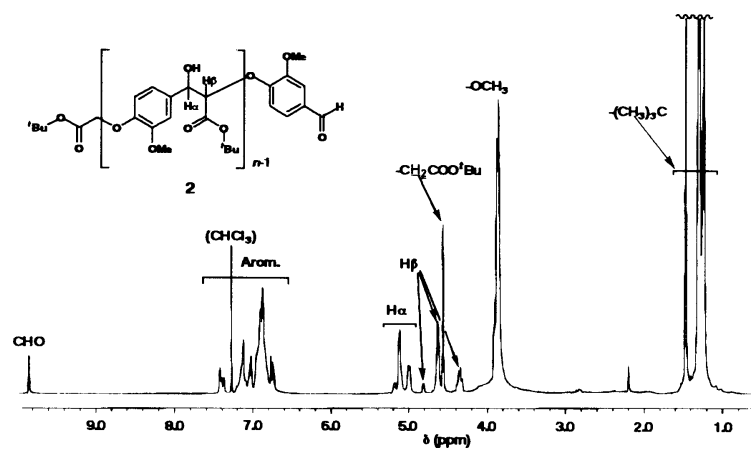

Fig. 2. $300 \mathrm{MHz}{ }^{1} \mathrm{H}-\mathrm{NMR}$ spectrum of oligomeric $\beta$-hydroxyl ester (2) $\left(\mathrm{CDCl}_{3}\right.$ solvent)

analysis (positive mode) of the acetate of $\mathbf{2}$, the signals of main ions were observed at $m / z 1214(n=4), 1522(n=5)$, $1830(n=6), 2138(n=7), 2447(n=8)$, and $2755(n=9)$, which are consistent with a sodium adduct. The difference in molecular weight between two consecutive main ions was 308 , which corresponded to the molecular weight of the repeating unit in the acetate of $\mathbf{2}$.

The number-average degree of polymerization of $\mathbf{2}$ was calculated to be about 7.2 (the polydispersity was 1.36) by gel permeation chromatography. Consequently, the polymerization reaction product (2) was identified to be oligomer of the $\beta$-hydroxyl ester; the repeating units of this oligomer was joined exclusively by $\beta-O-4$ linkages.

The oligomeric $\beta$-hydroxyl ester (2) was treated with $\mathrm{LiAlH}_{4}$ to give compound 3 in $73 \%$ yield. On the ${ }^{1} \mathrm{H}-\mathrm{NMR}$ spectrum of the acetate of $\mathbf{3}$ (compound 4) (Fig. 3), the chemical shifts of $\mathrm{H} \alpha(\delta 6.03, \mathrm{~m}), \mathrm{H} \beta(\delta 4.63, \mathrm{~m})$, and $\mathrm{H} \gamma(\delta$ $3.91-4.42, \mathrm{~m})$ were almost the same as those of trimers previously reported. ${ }^{3}$ In addition, the signals of methylene $(\delta$ $4.95)$ and ethylene ( $\delta 4.16$ and 4.31) protons of terminal structures appeared. The HSQC experiments indicated that the $\mathrm{C} \beta$ carbons at $\delta 79.8$ and 80.2 correlated with the $\mathrm{H} \beta$ proton at $\delta$ 4.65. The HMBC experiments indicated that there was a long-range correlation of the $\mathrm{C} 4$ carbons at $\delta$ 147.3 and 147.9 with the $\mathrm{H} \beta$ proton at $\delta 4.65$. All of these correlations confirmed that there was a $\beta-O-4$ ether linkage. On the MALDI-TOF mass spectrum of $\mathbf{4}$, the signals of the

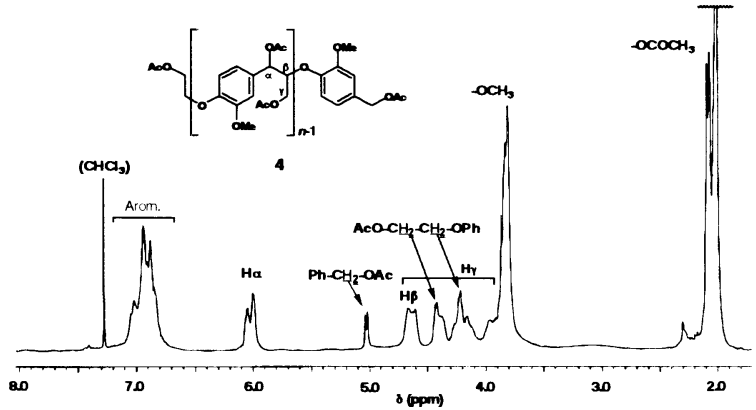

Fig. 3. $300 \mathrm{MHz}{ }^{1} \mathrm{H}-\mathrm{NMR}$ spectrum of the acetylated oligomeric $\beta$-O4 lignin model compound $\mathbf{4}\left(\mathrm{CDCl}_{3}\right.$ solvent $)$

main ions of each molecule were observed, and the difference in molecular weight between consecutive main ions was 280 , corresponding to the molecular weight of the repeating unit of $\mathbf{4}$. The number-average degree of polymerization of $\mathbf{4}$ was determined by gel permeation chromatography to be about 7.0 (the polydispersity was 1.42 ). The above results indicate that compound $\mathbf{3}$ is an oligomeric lignin model compound containing only $\beta-O-4$ interunit linkage.

Thus, $\beta-O-4$ type oligomeric lignin model compound $\mathbf{3}$ was synthesized in high yield by the stepwise nucleophilic addition polymerization of carbanion to the aldehyde group and subsequent reduction with $\mathrm{LiAlH}_{4}$.

The present synthetic method can be conveniently applied to synthesize various types of lignin oligomers or polymers. Examples of such products include phenolic oligomers, which may be obtained through the use of benzyl vanillin to terminate the reaction, and co-oligomers containing guaiacyl, syringyl, and $p$-hydroxylphenyl nuclei, which may be created by the use of a mixture of the corresponding starting monomers.

Acknowledgments The authors thank Dr. James L. Davis (University of Wisconsin, USA) for his advice.

\section{References}

1. Lai YZ, Sarkanen KV (1971) Lignins, occurrence, formation, structure and reactions. In: Sarkanen KV, Luwding CH (eds) Lignins. Wiley, New York, p 205

2. Lundquist K, Lundtrren R (1972) Acid degradation of lignin. Part VII. The cleavage of ether bonds. Acta Chem Scand 26:2005-2023

3. Iikka K, Asta TW, Hannu P, Jorma M, Gösta B (1994) Synthesis of hexameric lignin model compounds. Holzforschung 48:381-386

4. Nakatsubo F, Sato K, Higuchi T (1975) Synthesis of guaiacylglycerol- $\alpha$-guaiacyl ether. Holzforschung 29:165-168

5. Simone CB, Lucia B, Alberto B (1998) Synthesis of oligomeric mimics of lignin. J Chem Soc Perkin Trans 1 19:3207-3217

6. Nakatsubo F (1981) Enzymic dehydrogenation of $p$-coumaryl alcohol and syntheses of oligolignols. Wood Research 67:59-118

7. Hyatt A (1987) Synthesis of some tetrameric lignin model compounds containing $\beta-O-4$ and 5,5'-interunit linkages. Holzforschung 41:363-370 